\title{
sciendo
}

\section{The NIMBY effect towards wind energy instalments in Romania-myth or reality?}

\author{
Maria Alexandra MAASSEN \\ The Bucharest University of Economic Studies, Bucharest, Romania \\ maria_nichifor@hotmail.com
}

PICBE | 911

\begin{abstract}
In the past two decades wind energy has become one of the main sources of renewable energy used globally. With the expanding installments of wind turbines and wind parks, several issues have become apparent, especially in terms of closing in to human habitats, but also in terms of damages to the landscape, flora, fauna and other such issues. As more wind turbines are placed in order to achieve the global standards of renewable energy until 2020 and 2030 deadlines, a main issue of the NIMBY effect has also emerged, causing additional pressure on wind energy producers regarding placement, design, height and other elements of the wind turbines. The present study presents current public perceptions of Romanian residents on different placements of wind turbines, as the public becomes more aware of the new type of installments taking place today. Through the Delphi method based on interviews and questionnaires the study reveals current public perceptions and potential perspectives of the NIMBY effect in Romania. A main finding is that most respondents opposed placements of wind turbines in locations, such as residential areas, although wind turbines in Romania are generally placed in remote areas. This result reveals a public perception and consciousness regarding the protection of the human habitats against potential technological sources of discomfort, although renewable energy was perceived as a matter of interest for most participants. The relevance of the study lies in the novelty of the matter, as few studies have referred to NIMBY effects in Romania previously.
\end{abstract}

Keywords: NIMBY, wind energy, perceptions, wind turbine, renewable energy

\section{Introduction}

Wind energy has become one of the main sources of renewable energy. As the Europe 2020 and 2030 renewable energy targets have been imposed more and more wind turbine installments occurred, which led to the proximity of these technological devices to residential areas, natural landscapes and other such placements, which make their acceptance in time more difficult. The NIMBY or the "not in my back yard effect" was caused through this phenomena of expanding wind energy installments and their perceived negative effects and has been a frequent matter of debate in the past years. More authors have described the NIMBY effect, namely "protectionist attitudes of and oppositional tactics adopted by community groups facing an unwelcome development in their neighborhood" as Dear (1992) defines it. Pol et al (2006) mention the NIMBY effect may be defined as "social rejection of facilities, infrastructure and services location, which are socially necessary, but have a negative connotation". The NIMBY syndrome has not only been associated with environmental issues, such as the placement of wind turbines in certain regions as close to residential areas, but also with other causes, such as hazardous waste sittings or sittings of other public services, including nursing homes, public housings, prison etc. (Davis, 1993, Lester and Bowman, 1983).

Several authors have inquired the reasons of these types of protectionist attitudes against wind turbine placements in certain regions. Broekel and Alfken (2015) for example, mentioned the negative perceived perceptions against wind turbine placements due to their 
interference with natural landscapes and touristic objectives. The authors mention there is a discrepancy of the presence of wind turbine placements and historical places, considered unfit to be in proximity to one another, thus, the need for consistency between the natural (original) and artificial environment. Wolsink (2000) has also confirmed such reasons and added more causes of perceived disturbances of wind energy installments, such as: noise pollution causing annoyance, damaging fauna, such as birds, unreliability of the energy supply, the (supposed) expensiveness of wind as a source of energy, design of wind turbines, that could cause landscape damage. Another author, Martin (2017) mentioned also other identified concerns of citizens depending on the region, such as wind turbines interfering with landscape and birds and bats populations, as well as being noisy and even decrease the properties value in the region, injure people and reduce access to a quiet habitat in the neighborhood.

Thus, the issue of opposing placements of wind turbines has been a significant subject of conflict and debate in the past years and continues nowadays, as more wind energy installments expand in other regions. Moreover, there is an intrinsec political element to energy security (Dudau, R. and Nedelcu, A.C., 2016). The objective of the present study is to offer an overview of public perceptions of Romanian residents over potential issues caused by placements of wind turbines in different geographic areas, as well as factors, that could increase the acceptance of these technological installments, based on the sample of selected participants. The matter of the NIMBY effect in Romania is mostly a novelty topic as the country has a large surface and most wind turbines are placed in remote areas with little or no population, however, causing certain reactions in the case of locations in certain "sensitive" regions, as the research will indicate. Practically, the objective of the present study was to analyze if the NIMBY effect is also present in Romania despite general remote locations of wind turbines. The study was based on a sample of perceived perceptions of Romanian citizens and the potential presence of the NIMBY effect against placement of wind turbines in certain regions, which already offer certain restrictions for wind turbine placements depending on locations or other factors.

\section{Literature review}

Wind power was the main installed source of energy in Europe in 2017, accounting for 55\% of the power installations and adding in $201715638 \mathrm{MW}$ of new wind power capacities (Wind in Power, 2017). The offshore installations in 2017 grew 101\% comparing to the level of 2016, while the onshore installed capacities of the year were up 14.3\% comparing to 2016. The expansion of installed wind turbines has led to several perceptions from local communities, populations and institutions, leading to the not in my back yard or NIMBY effect in some regions due to their effects or potential perceived impacts caused by their presence in the local landscape.

A main factor of discussion is the visual landscape impact of wind turbines for the population neighboring it. Some studies mention citizens used to industrial and technological landscapes within their daily lives are more likely to accept wind turbines or other such technological installments easier than the ones used with natural landscapes, as well as

previous use and visual quality of the selected sites are factors, that contribute to their increased acceptance (Petrova, 2016). Dima, et al., (2017) mentions the importance of excellence and convergence in every sustainable model. Pedersen and Halmstad (2003) 
emphasize the noise annoyance as a main factor of discomfort when it comes to installing wind turbines, as the residents realize it usually after wind turbines are built and cause stress, hearing problems and sleep disturbance, as also seen in Table 1. Wolsink (2007) also describes four types of attitudes characteristic to NIMBY: the traditional concept of the NIMBY, namely that technology is accepted, but there is local rejection because of concerns over personal impacts of the population due to these installations, secondly the continuous rejection of the placements, thirdly rejection of installments as an opinion against a certain local project is formed and last the rejection of the project due to perceived negative impacts, such as landscape damage, although the technology itself may be accepted.

Other studies confirmed the fact that the way the project is presented to the local population is highly important when it comes to acceptance or rejection, thus, implying it is more a matter of perception from the citizens than the actual potential or factual disturbance by the wind turbine placements (Ek and Person, 2014). Ownership, location and community involvement are also factors strongly linked to the acceptance or rejection of wind turbines, some studies indicating that private ownership was perceived as much more negative than cooperative or local municipality ownership or placement in recreational areas or mountains, as well seemed to have a negative impact on the population's perception (European Commission, 2014).

Table 1. NIMBY effect contributing factors

\begin{tabular}{|c|}
\hline Main factors contributing to the NIMBY effect \\
Noise and annoyance \\
Landscape impact \\
Damages on fauna and flora \\
Shadow flickering \\
Health issues (hearing loss, visual epilepsy, etc.) \\
Lack of involvement of communities in projects location and in decision making \\
Lack of financial benefits for local citizens \\
Negative impact on local properties due to technology placement
\end{tabular}

Source: (Ek and Person, 2014), (Petrova, 2016), Wolsink (2007)

Jones and Eiser (2009) mention the involvement of the community and engages discussion regarding the future project of wind turbines would increase acceptance, as communities generally fear negative changes brought by the installed technology for the community and as such usually oppose it. The important aspects taking into account are the political context, the geology and the operating conditions (Tanțău, A.D. and Khorshidi, M., 2016). Another finding of other authors was that in situations where communities and individuals were involved in the decision process of such wind turbine projects and in the cases where they were financially rewarded, local citizens did not oppose wind turbines technology and even positively perceived them in the visual landscape (Warren and McFadyen, 2010).

Thus, the wind power installments have caused several controversial attitudes towards their placement depending on subjective and objective factors related mainly to the citizens and communities that have led to the need of finding solutions from the part of wind 
power institutions in order to decrease the risk of their projects being rejected or legally combated after their construction.

\section{Methodology}

The research was done based on interviews and questionnaires through the Delphi method, by involving a sample of 30 individuals regarding the topic of the placement of wind energy installments. Most of the participants mentioned they were informed about wind energy or were working in research, study or in the production of wind energy, however, they stated they had not been involved before in a questioning regarding the matter of NIMBY effect on wind power placement. The sample was selected also based on this fact, that there was some prior information available to the participants regarding wind energy installments and the NIMBY effect before actually doing the research in order for them to be able to provide some documented answers.

The participants were classified according to certain characteristics, such as age, education level, residence and if they owned their place of residence or rented. Most participants (83\%) were citizens between 18 and 40 years old, while only $7 \%$ were between 40-60 years of age and the rest above 60 years of age. Regarding the education level $83 \%$ had graduated Bachelor and/or Master studies, while 17\% had a PhD. All respondents resided in Romania, 87\% in Bucharest and the rest in other regions, such as Ploiești and Târgoviște and all lived in urban areas.

$57 \%$ of the respondents owned their apartment or house, while the rest did not own their place and either rented or stayed with parents, roommates, college shared apartments and other such cases. This aspect was inquired as residents owning their own houses may have stronger opinions on such wind power placements in comparison to the ones, that do not own their places yet. Most selected individuals lived in Bucharest at a distance of minimum $200 \mathrm{~km}$ from wind turbines or wind parks, while only $3 \%$ of the participants lived close by $(1-2 \mathrm{~km})$ to wind turbine installments.

The study was composed of two parts. The first part referred to the public perceptions of the participants regarding placements of wind turbines in different geographic landscapes, as well as potential sources of discomfort from these installments, while the second part referred to characteristics of wind turbines or other motivational factors, that would contribute to the acceptance of these placements in residential areas of the participants or other regions. Furthermore, in the second part of the study the respondents mentioned their perspectives on investing in shares in a wind energy company and in installing a wind turbine in order to ensure their energy independence.

Two hypotheses were also formulated:

H1. Most Romanian respondents would agree to placing wind turbines in residential areas.

H2. The most important factors of increasing acceptance of wind turbines close to the residence of individuals are financial stimulation and involvement of the citizens in the construction phase regarding wind turbine placement.

The time span of the research was between October 2018 and December 2018. 


\section{Results and discussions}

The participants answered questions regarding the visual impact of the placement of wind energy technology in different regions, depending on height, archeological site, protected area, as well as regarding sources of discomfort from these installments and potential methods to increase acceptance. The first question referred to the perception of the respondents regarding the placement of the wind turbines in more regions, such as on a field, on hills, mountains or in other spaces, such as offshore, protected areas, residential areas and other.

As expected most individuals agreed for the placement of wind turbine installments on fields (86\%), while only $7 \%$ mentioned they would not agree and the rest did not know what to answer. An unexpected result was that $60 \%$ of the Romanian participants would not agree to wind turbine placement in residential areas, as illustrated in Figure 1, although 96\% of them mentioned they have an interest for sustainability, renewable energy usage and ecology.

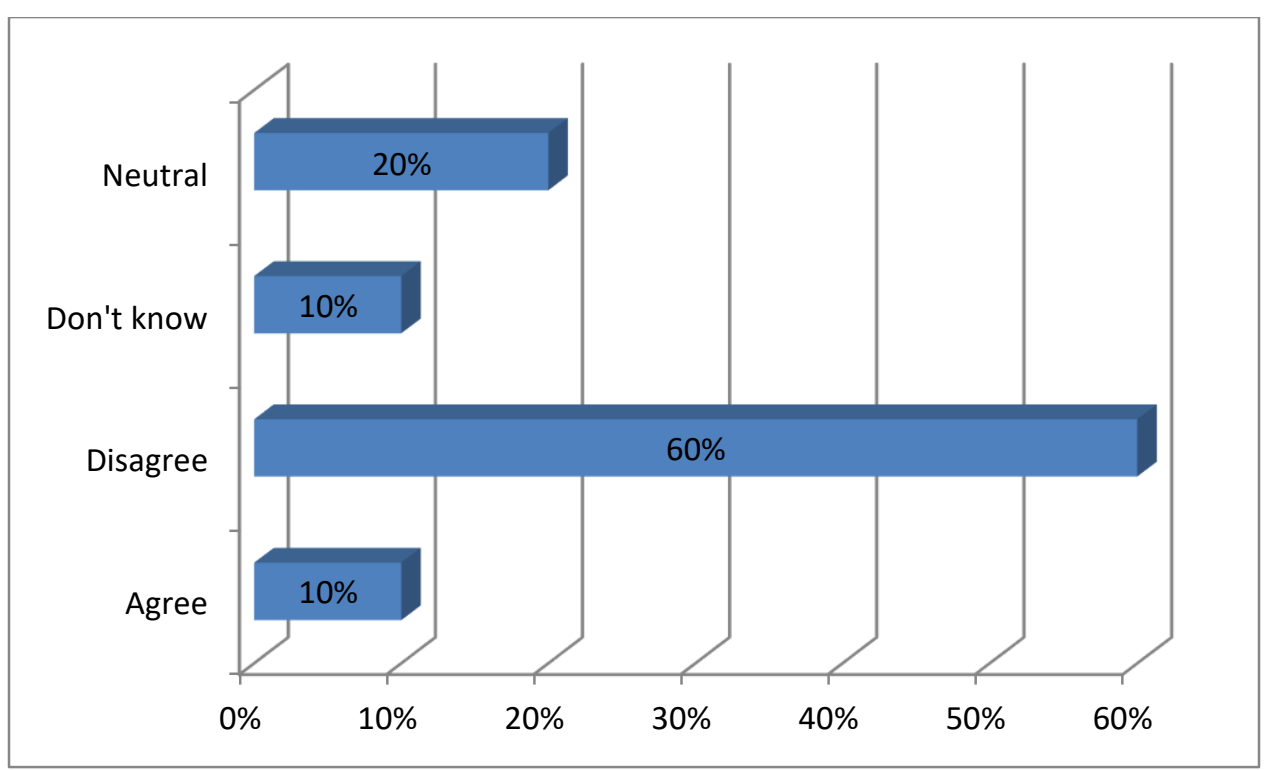

Figure 1. Perception of the respondents regarding placement of wind turbines in residential areas

Source: Author's own research

Other regions, that were mentioned as potential placement surfaces were also considered as not being proper locations for wind turbines, such as close to archaeological sites and in protected areas, as shown in Table 2. Another unexpected result was that most participants would agree to placing wind turbines on high plateaus, such as hills and mountains, as generally these were considered as damaging the visual landscape through the addition of extra elements with large height. Furthermore, the degree of discomfort the participants would feel by neighboring wind turbine installments was inquired. $40 \%$ of the respondents mentioned they would feel a high degree of discomfort, while $33 \%$ stated they would be neutral towards it. Only $7 \%$ mentioned they would not feel at all bothered by this aspect, while $20 \%$ mentioned they would be bothered slightly. 
Regarding sources of discomfort from these type of installments most respondents mentioned the noise (87\%), while similar percentages mentioned environmental damage/health issues derived from affecting flora and fauna (27\%), shadow flickering (23\%) and affecting the regional landscape (30\%).

Table 2. Perceptions of the respondents towards placement of wind turbines in geographic regions

\begin{tabular}{|l|c|l|}
\hline \multicolumn{3}{|c|}{ In the proximity of archaeological sites } \\
\hline Disagree 70\% & Neutral 17\% & Don't know 13\% \\
\hline \multicolumn{3}{|c|}{ Protected areas } \\
\hline Disagree 83\% & Neutral 13\% & Agree 4\% \\
\hline \multicolumn{3}{|c|}{ Placement on mountains } \\
\hline Disagree 20\% & Neutral 16\% (Don't know 7\%) & Agree 57\% \\
\hline \multicolumn{3}{|c|}{ Placement on hills } \\
\hline Disagree 10\% & Neutral 4\% (Don't know 3\%) & Agree 83\% \\
\hline \multicolumn{3}{|c|}{ Offshore } \\
\hline Disagree 13\% & Neutral 17\% (Don't know 7\%) & Agree 63\% \\
\hline
\end{tabular}

The study also revealed the perceptions of the respondents regarding potential characteristics or aspects of wind turbines placement, that could contribute to increasing acceptance.

As expected most individuals found it important that wind turbines have light colors, such as grey, white, blue, etc. (70\%), while the rest thought of this aspect as being neutral and not affecting acceptance of such placements. Another finding was that grouping wind turbines differently, such as one alternative with more wind turbines of smaller sizes or the other one with fewer wind turbines with larger heights, was considered as not having an impact on the acceptance of these and thus, being a neutral element. Only approximately $20 \%$ of the respondents thought either of the alternatives could contribute positively to the increase of acceptance significantly.

The respondents also referred to the minimal distance of wind turbine placement in order not to produce discomfort, namely $20 \%$ mentioned a distance of at least 200 meters- 1 kilometer, $36 \%$ mentioned a distance of $1-3 \mathrm{~km}, 10 \% 3-4$ kilometers, $4-50 \mathrm{~km} 20 \%$ and $14 \%$ mentioned at least $50 \mathrm{~km}$ distance. The participants were also asked which of the factors in Table 3, they would consider in order to accept wind turbines close to their residence. A surprising result was the fact that most respondents mentioned an expertise report regarding the fact that the wind turbine/s have minimum impact on the environment (43\%), as mentioned in Table 3, which surpassed the amount of persons involving a financial supplement for their acceptance $(27 \%)$. Only $7 \%$ of the people chose the alternative of involving citizens in the construction phase, as to visualize and choose the location depending on geographical region, size and distribution of wind turbines. 
Table 3. Motivational factors for respondents to accept wind turbines close to their own residential areas

\begin{tabular}{|l|c|}
\hline $\begin{array}{l}\text { Potential motivating factors for acceptance } \\
\text { of wind turbines in residential areas of the } \\
\text { respondents }\end{array}$ & Percentage \\
\hline $\begin{array}{l}\text { 1. Expertise report regarding minimum } \\
\text { impact of the wind turbine/s on the } \\
\text { environment }\end{array}$ & $43 \%$ \\
\hline $\begin{array}{l}\text { Involvement of citizens in the } \\
\text { construction phase (for selecting } \\
\text { location, etc.) }\end{array}$ & $7 \%$ \\
\hline 3. Financial & $27 \%$ \\
\hline 4. Only if no noise and no shadow \\
flickering occur
\end{tabular}

The second part of the research revealed that $63 \%$ of the participants would certainly invest in a small sized wind turbine in order to ensure their energy independence, while 33\% mentioned they would be interested to a certain degree in investing in such an installment. Only 1 respondent mentioned they would not be interested in this option.

Furthermore, 43\% would invest in shares of a wind energy company, while the rest of the participants mentioned they did not know yet if they would make such an investment due to lack of information, interest or possibilities.

\section{Conclusion}

As a first conclusion, the first hypothesis of the study regarding the fact that most Romanian respondents would agree to placing wind turbines in residential areas was not confirmed by the study, as the majority of the selected participants (60\%) opposed this idea. They mentioned also potential negative causes, such as noise and visual landscape damage as factors contributing to their reaction against such placements and the concern of damaging their life quality. Secondly, the expected solutions for increasing wind turbine placements acceptance, namely, financial stimulation and involvement of the citizens in the construction phase regarding wind turbine placement, were also infirmed by the study, as the majority of the questioned respondents stated actually they would be more convinced of an expertise report regarding minimum impact of the wind turbine/s on the environment than the previously named factors. The participants were more concerned that their residential areas would not be damaged by such placements, in terms of visual landscape, damage to the environment and potential disturbance factors for their health than mainly a financial stimulation. Although wind turbines are usually placed in remote areas in Romania 
participants of the study having a certain degree of information on this matter were cautious mostly with answering the acceptance of wind turbines and had similar views as previous studies participants, as for example, opposing wind turbine instalments in archaeological regions or protected sites, as well as potential placement in their residential areas. However, the Romanian participants, as mentioned seemed more concerned with the wind energy producers proving through an expertise report, that this technology placement would not affect their environment compared to other studies, such as that of Warren and McFadyen (2010), where the citizens agreed already for a financial stimulation in return for the placement of wind power technology in their areas and even positively perceived it afterwards.

The issue of wind turbines placement has become a main strategic problem for the management of several wind energy producers, installing this technology in more geographic regions. Though, it is not fully proven whether or not wind turbines are actually causing problems, such as health issues for the residents around it or their unpleasing visual perceptions of the wind technology in the landscape, the NIMBY effect can be a threat for the potential projects in the field, as they can be legally combated in any phase of development and thus, representing a challenge in terms of strategic management for such companies in ensuring a smooth construction and production of their projects.

Wind power instalments have become however an undeniable presence in several landscapes, which have been proven to be able to have negative impacts on flora and fauna, when their instalment is done without prior strategic planning as to avoid main regions or routes of certain species. The sustainability issue of wind power instalments represents thus, also nowadays a main challenge for wind energy companies in order to produce clean energy, but also avoid the destruction of the environment. That is why the topic of the NIMBY effect has taken such proportions globally, as technology approaches citizens and natural habitats and cause adjusting and perceived visual, social and environmental problems of acceptance.

A future objective is to expand the present study to a larger sample of informed citizens on the matter and also observe how the expansion of wind energy in Romania will evolve, as more of these type of technologies are installed by foreigners as well for their own countries' production, which will certainly cause specific reactions from the part of the local residents.

\section{References}

Broekel, T., Alfken, C. (2015). Gone with the wind? The impact of wind turbines on tourism demand. MPRA, 1-22. Retrieved from https://mpra.ub.unimuenchen.de/65946/1/MPRA_paper_65946.pdf.

Davis, C.E. (1993). The Politics of Hazardous Waste. Englewood Cliffs. NJ: Prentice-Hall.

Dear, M. (1992). Understanding and Overcoming the NIMBY Syndrome. Journal of the American Planning Association, 58(3), 288-300.

Ghinea, V.M., Dima, A.M. and Hadad, S., 2017. Excellence Model for Sustainable Convergence in the EU Higher Education. Amfiteatru Economic, 19 (Special No. 11), pp. 11071122.

Dudau, R. and Nedelcu, A.C. (2016), “Energy security: between markets and sovereign politics", Management \& Marketing. Challenges for the Knowledge Society, Vol. 11, No. 3, pp. 544-552. DOI: 10.1515/mmcks-2016-0015. 
Ek, K., Person, L. (2014). Wind farms - Where and how to place them? A choice experiment approach to measure consumer preferences for characteristics of wind farm establishments in Sweden. Ecological Economics, 105, 193-203, https://doi.org/10.1016/j.ecolecon.2014.06.001.

European Commission (2014). Public support for wind farms increases with community participation. Retrieved from http://ec.europa.eu/environment/integration/research/newsalert/pdf/windfarms_ support_community_participation_Sweden_energy_387na1.pdf.

Jones, C.R., Eiser, J. R. (2009). Identifying predictors of attitudes towards local onshore wind development with reference to an English case study. Energy Policy, 37, 4604-4614, doi:10.1016/j.enpol.2009.06.015.

Lester, J.P., Bowman, A. (1983). The Politics of Hazardous Waste Management. Durham: Duke University Press.

Martin, S.L. (2017). Wind Farms and NIMBYs: Generating Conflict, Reducing Litigation. Fordham Environmental Law Review, 2(3), 427-468.

Pedersen, E., Halmstad, H. (2003). Noise Annoyance from Wind Turbines - a € Review, Swedish Environmental Protection Agency. Retrieved from https://www.naturvardsverket.se/Documents/publikationer/620-5308-6.pdf.

Petrova, M.A. (2016). From NIMBY to acceptance: Toward a novel framework d VESPA d For organizing and interpreting community concerns. Renewable Energy, 86, 12801294.

Pol, E., Masso, A.D., Castrechini, A., Bonet, M.R., Vidal, T. (2006). Psychological parameters to understand and manage the NIMBY effect. Revue européenne de psychologie appliquée, 56, 43-51.

Tanțău, A.D. and Khorshidi, M. (2016), "New business models for state companies in the oil industry", Management \& Marketing. Challenges for the Knowledge Society, Vol. 11, No. 3, pp. 484-497. DOI: 10.1515/mmcks-2016-001.

Warren, C.R., McFadyen, M. (2010). Does Community Ownership Affect Public Attitudes to Wind Energy? A Case Study from South-West Scotland. Land Use Policy, 27 (2/4), 204-13.

Wind in power (2017). Annual combined onshore and offshore wind energy statistics. Retrieved frm https://windeurope.org/wp-content/uploads/files/aboutwind/statistics/WindEurope-Annual-Statistics-2017.pdf.

Wolsink, M. (2000). Wind power and the NIMBY-myth: institutional capacity and the limited significance of public support. Renewable Energy, 21, 49-64. 